\title{
RACIONALIDAD E IMAGINARIO SOCIAL EN EL DISCURSO DEL ORDEN
}

\author{
Creyó haber nacido para provecho del mundo y no para \\ el propio.
}

Lucano, Farsalia II, 383

\section{-El dispositivo del poder: discurso del orden e imaginario social}



a historia del reparto del poder y su correlación en lo social con jerarquías desiguales ha sido secularmente acompañada por un dispositivo de legitimación y sostén no exento de complejidad y doble vertiente. Convergen en este dispositivo, por un lado, la construcción de un discurso del orden que asigna al resultado y producto social en una dada relación de fuerzas, una propiedad natural o divina: la de ser un orden necesario «para el provecho del mundo» aunque se trate, en verdad, de un cierto orden, o sea, orden impuesto "para el propio» provecho del clan, la tribu o el pueblo vencedor, determinada comunidad o la clase privilegiada.

Integra este dispositivo, por otro lado, la inserción del discurso del orden en montajes de ficción, soportes mitológicos y prácticas extradiscursivas como ceremonias, banderas, rituales, cánticos e himnos, distribución de espacios, rangos y prestigios, etiquetas, y otras de no menos variado tipo como heráldicas, diplomas, tatuajes, marcas, apelación a los ancestros, tumbas, símbolos funerarios, manejos de ruidos y silencios, escenas que ponen en relación al hombre con la solemnización de la palabra.

Todas estas prácticas de solicitación y manipuleo del psiquismo humano pueden identificarse bajo el rótulo de imaginario social, en el que se hacen materialmente posibles las condiciones de reproducción del discurso del orden.

El «discurso del orden» y el «imaginario social» concurren y convergen en el «dispositivo del poder», del que constituyen instancias distintas pero no independientes.

Nadie duda de la complejidad del fenómeno del poder cuyos análisis pueden pasar y han pasado de una dirección macrofísica en los estudios a un polo microfísico. La primera dirección que nos ocupará en este trabajo responde a una concepción clásica del poder ligado al problema de la soberanía. Poder y Soberanía son el anverso y el reverso de un mismo problema al que se interpela con el pensamiento jurídico político de los siglos XVI y XVII. Combatiendo por el poder real, defendiendo el derecho supremo del soberano, único capaz de imponer por encima de los individuos particulares la voz universal de la razón, necesaria a un siglo intensamente convulsionado por las crisis religiosas y políticas, Thomas Hobbes construyó el modelo más acabado del poder absoluto. Es sabido que este modelo, el más extremo del absolutismo estatal, fue el del Leviathan, «dios mortal al que debe- 
mos, bajo el Dios inmortal nuestra paz y nuestra protección» ${ }^{1}$ al que Hobbes, por la vía del pacto legítimante, le reconoce un poder y una fuerza tal que el terror que inspiran le permiten modelar la voluntad de todos. Por el pacto los particulares intentan escapar a la guerra de todos contra todos y renuncian a ejercer su derecho natural para obtener en compensación, seguridad a condición de que todos hagan lo mismo. Como esta reciprocidad no puede esperarse de la voluntad de cada individuo aislado, una potencia incontestada e incontestable por el exceso de su poder debe asegurar el monto desbordante de fuerza y coacción que permita en pleno estado de naturaleza, instaurar la sociedad civil: el soberano y su potencia. El soberano representa la voluntad y la unidad del cuerpo político, pero no es una parte de este cuerpo ya que no está ligado por la convención que los sujetos suscriben entre sí y no con el soberano. Más bien, dice Hobbes, «la soberanía es un alma artificial que da la vida y el movimiento al cuerpo» (Lev. Int. p. 5). El soberano es el legislador, el que nombra los Consejos, controla las doctrinas y las opiniones, reparte las recompensas y los castigos. Dueño de la espada de la guerra en el gesto en que la levanta, levanta la espada de la justicia, la jus gladii, y se erige a una en injusticiable y amo de la ley. Para los demás, o sea para los sujetos, regla y derregla el uso del derecho, designa los magistrados, establece y deroga las leyes, fija en su marco la dimensión de lo valioso y lo disvalioso, lo justo y lo injusto.

Esta injusticiabilidad del príncipe aparece expuesta con nitidez por Hobbes en De Cive, Sección II, «El Imperio», Cap. VI, punto 12, en el doble ámbito de los hechos y el derecho: «En fin, de que cada particular ha sometido su voluntad a la voluntad del que posee la potencia soberana en el Estado, de tal suerte que no puede emplear contra él sus propias fuerzas, se sigue manifiestamente que el Soberano debe ser injusticiable sin que importe lo que emprenda. Puesto que del mismo modo que naturalmente (de hecho) no se puede castigar a alguien si se carece de las fuerzas suficientes para ser el amo, tampoco se puede castigar a alguien legítimamente (de iure) si no se cuenta para ello con fuerzas legítimas suficiente» ${ }^{2}$.

Sobre la interpretación del poder en T. Hobbes véanse los capítulos 4 y 5 del libro Thomas Hobbes, de Michel Malherbe, París, 1984, ed. Urin y la segunda (La teoría política) de Thomas Hobbes y los orígenes del estado burgués, Buenos Aires, 1973, de Guillermina Garmendia de Camusso y Nelly Schanaith. En cuanto al problema de la ideología en Hobbes el artículo de Ezequiel de Olazo, «Hobbes y el análisis ideológico» en Revista Latinoamericana de Filosofía, Vol. VI, N. ${ }^{\circ}$ 1, marzo 1980, Buenos Aires. Lo sustancial de la obra política de Hobbes está contenido en The Elements of Law (1640), De Cive (1642) y Leviathan (1651). La obra de Hobbes está en función de los intereses prácticos de las luchas políticas en Inglaterra del siglo XVII, en las que estuvo comprometido. Los comienzos de la rebelión contra Carlos I en Escocia e Inglaterra en la década del 30 al 40, lo apartaron, según Aubrey su biógrafo contemporáneo, casi por completo de la matemática, centrándose en la filosofía política. Emigró en 1640 a Francia donde estuvo 10 años y volvió a Inglaterra después de la derrota y ejecución de Carlos I, conservando la amistad de Carlos III luego de la restauración de los Estuardos en 1660.

2 Para Raymond Polin, introductor de la ed. francesa de De Cive, al mantener Hobbes la idea de un derecho natural negativo, de una justicia natural negativa, integra en éstos los principios del positivismo jurídico, anticipándose en lo esencial a Hans Kelsen. Véase De Cive o los fundamentos de la política, París, Sirey, 1981, p. 51. 
A la luz de esta injusticiabilidad, se comprende ahora el embarazo jurídico y político que un siglo más tarde de Hobbes habría de emerger en uno de los debates más graves de la historia, cuando en 1793 la Convención Nacional tiene que juzgar al último Rey del Antiguo Régimen, al derrotado de Valmy y prisionero en Temple. Sustentando la injusticiabilidad y la imposibilidad jurídica del proceso, Morisson su defensor reproduce el argumento de Hobbes: «Para juzgar a Louis XVI es necesario que haya una ley preexistente que pueda serle aplicada... El código penal no contiene ninguna disposición que pueda ser aplicada a Louis XVI. Aún en el tiempo de sus crímenes existía una excepción a su favor, yo quiero hablar de Constitución». Injusticia de derecho, sus acusadores quedan de este modo remitidos a la cuestión de hecho y apresados por ende en el texto hobbesiano: al Rey, al Capeto no hay que juzgarlo de iure sino combatirlo. Para Saint Just: «La opinión de Morisson que conserva la inviolabilidad y la del comité que quiere que se lo juzgue como ciudadano, son igualmente falsas. En cuanto a mí digo que el Rey debe ser juzgado como enemigo». No se puede reinar inocentemente, el crimen de este hombre es el de haber sido rey y no hay punto medio, debe reinar o morir. «Las formas del procedimiento no están en la ley civil, sino en el derecho de gentes... Un día nos asombraremos de que en el siglo XVIII se haya avanzado menos que en los tiempos de César. El tirano fue inmolado en pleno senado, sin otras formalidades que veintidós golpes de puñal y sin otra ley que la libertad de Roma. Y hoy se hace con respeto el proceso de un hombre asesino de un pueblo sorprendido en flagrante delito con la mano en la sangre y en el crimen. Aquellos que atribuyen alguna importancia al justo castigo de un rey jamás fundarán una República». En el cancel del argumento de hecho, poco añade luego la voz jacobina de Robespierre: «El rey no es un acusado. Ustedes no tienen que dictar una sentencia a favor o en contra de un hombre, sino adoptar una medida de salud pública, ejercer un acto de providencia nacional. Louis fue rey, la República está fundada. La cuestión famosa que os ocupa está reglada por estas solas palabras... El derecho de castigar el tirano y el de destronarlo es la misma cosa, uno no computa otras formas que el otro. Louis debe morir porque es necesario que la patria viva» ${ }^{3}$.

La injusticiabilidad del poder soberano, la emanación del derecho y sus contornos de su voluntad suprema, la circunstancia de que el soberano constituya un ser natural sólo frente a los otros soberanos, y no-natural frente a sus sujetos -puesto que su derecho es único- son los indicadores decisivos de este otro elemento esencial del dispositivo del poder que no aparecía en nuestro esquema inicial y que lo integra junto con el discurso del orden y el imaginario social: «la fuerza».

Hemos percibido a Hobbes aludir a este tercer elemento, tanto en el argumento de hecho como en el de derecho, en algunos breves pasajes del $D e$ Cive y el Leviathan. El capítulo XVII de este último tratado contiene su fórmula más simple: «... las convenciones sin la espada no son más que palabras carentes de la fuerza para dar a los hombres la menor seguridad» y el 
XX identifica a la fuerza como el origen común de los tipos de República que examina en este texto, la República de adquisición (o conquista) y la República de institución: «La República de adquisición es aquella en que el poder soberano se adquiere mediante la fuerza, allí donde los hombres sea individual o colectivamente (por la mayoría de los sufragios) por miedo a la muerte o a las cadenas, autorizan todas las acciones del hombre o de la asamblea que tiene poder sobre sus vidas y libertades.

Esta especie de dominación o de soberanía difiere de la soberanía de institución, solamente en esto: que los hombres que eligen su soberano lo hacen por miedo de unos a otros, y no por miedo a quien instituyen. Pero en este caso se someten al que es temido. En ambos casos lo hacen por temor y deben tomar nota aquellos que sostienen que son nulas todas las convenciones que proceden del miedo a la muerte o a la violencia. De ser cierto esto, sería imposible que ningún hombre estuviese obligado a obediencia en ninguna clase de República... ».

En los dos casos existe pacto y en los dos casos existe temor, la diferencia radica en que las repúblicas por institución crean la desigualdad civil, en tanto que el pacto en las de adquisición consagra una relación desigual de dominación adquirida naturalmente.

La fuerza es el elemento constitutivo del poder, el que lo produce, pero la fuerza o la violencia se frustraría de no articularse en dispositivo con el discurso del orden y el imaginario social, que constituyen las condiciones de reproducción del poder producido, los garantes de la continuidad del poder conquistado o instituido con base en la fuerza. En el interior del dispositivo del poder, el discurso del orden y el imaginario social reactualizan la fuerza y la transforman verdaderamente en poder, haciéndolo constante y socialmente transmisible. Este cambio no es de grado sino de cualificación, con él el poder se hace operativo para la cohesión del grupo o la sociedad. Transformada la fuerza en poder, el discurso del orden y el imaginario social aseguran la presencia del poder y los efectos de la fuerza aun estando ésta ausente.

Fuerza, discurso del orden e imaginario social varían en sus modos de articularse, intersectarse y agruparse dentro del dispositivo del poder, según cambios históricos en que se suceden diversas coyunturas económicas, políticas e ideológicas o mutaciones estructurales revolucionarias en los sistemas de producción. Estas rotaciones en las modalidades de interferencia y combinación de los elementos del dispositivo del poder, el hecho de que el discurso del orden y el imaginario social tengan distintos puntos de anclaje entre sí y en su incardinación con el juego de las relaciones de fuerza conforme a su estado histórico, la densidad de contacto o separación entre ellos, su respectivo peso específico que va de la mayor o menor evicción o evacuación de cada uno en el dispositivo o de la mayor o menor transparencia del dispositivo en la estructura social opaca por naturaleza, depende básicamente de dos factores. El primer factor es endógeno y relativo a la circunstancia de que, dentro del dispositivo, discurso del orden e imaginario social son heterogéneos y cumplen distinto papel y función. Pertenecen, en rigor, a tópicos disímiles: veamos sus lugares correspondientes.

El discurso del orden es el lugar de la razón. Pertenece al ámbito cog- 
noscitivo, al de la teoría y las represenaciones racionales. En este lugar, doctores del derecho, prudentes, juristas (esos profesores de racionalidad), intérpretes y glosadores hacen su obra. Buena parte de este dominio lo satisfacen también la moral, la filosofía política y la religión, aisladamente o en conjunción con el segmento jurídico del discurso del orden al que suministran los últimos fundamentos, los referentes trascendentes divinos o seculares, y las ficciones del reino vaihingeriano del «como-si». Es éste el topos de legitimación en el dispositivo del poder, el de los juegos enunciativos y las reglas de justificación. Cuando asume normalmente la forma de ciencia del derecho predominan el análisis de conceptos, los criterios descriptivos y clasificatorios de las conductas que las normas prohiben o autorizan, la lógica de los directivos y la gramática de los operadores deónticos, es decir, el conjunto de los procedimientos lógico-metodológicos cuya reconstrucción se asigna a la historia interna de la ciencia. En este contexto de racionalidad, la demanda de la ciencia jurídica a la filosofía en procura de sus fundamentos (que es por definición una demanda ideológica) ha sido un movimiento de báscula entre la noción de Verdad-garante y la más flexible de rational acceptability, luego de la desconstrucción de aquella noción en nuestros tiempos por la filosofía.

Pero el discurso del orden es también el espacio de la ley. En este espacio, la fuerza encuentra dentro del dispositivo del poder su modo más racional de comunicación social al apropiarse de las técnicas con que las normas jurídicas la transmiten y transportan con el nombre de coerción, coacción, y sanción, es decir, con los mecanismos de obediencia y control social del derecho.

El espacio de la ley es espacio de razón. La ley es fuerza-razón en un doble sentido: razón en cuanto al tipo formal de las estructuras lógicas que comunican la fuerza, y razón en cuanto en ella y a través de ella se producen las operaciones ideológicas de justificación del poder. Antes de abandonar la terminología del Leviathan, paradigma de lo absoluto entre las concepciones clásicas del poder, es útil ver a Hobbes centrar en la razón el paso a la ley civil emergente del pacto productor de la soberanía. La pérdida de la libertad propia del estado de naturaleza sólo se justifica, en efecto, en el cálculo racional de las ventajas que proceden del sacrificio del derecho natural de todos a todo: la paz, la seguridad, la protección y preservación de la vida. Sólo la conservación de la vida puede ser la respuesta de la razón a una pregunta revestida con todas las apariencias de lo incongruente: ¿cómo un pacto o una convención entre particulares puede engendrar la relación de soberanía, que es una relación de poder y no sólo de fuerza, y generar un campo de obligaciones y de sujeciones unilaterales?

$\mathrm{Al}$ indicar Hobbes que la conservación de la vida es la respuesta de la razón, señala también que es la vida el único derecho inalienable e intransferible. De este modo, abre el derecho de resistencia, el margen de la libertad en el poder absoluto, cuando éste pierde su capacidad de protección: «La obligación de los súbditos -dice- para con el soberano se sobreentiende que dura tanto como el poder mediante el cual éste es capaz de protegerlos. Pues los hombres no pueden enajenar el derecho que tienen por naturaleza a protegerse cuando ningún otro puede hacerlo. La soberanía es el alma de 
la república y una vez separada del cuerpo, los miembros ya no reciben su movimiento de ella. El fin de la obediencia es la protección...» (Lev. Cap. XXII).

Ahora bien, el dispositivo del poder exige como condición de funcionamiento y reproducción que la fuerza y el discurso del orden legitimante, estén insertos en una estructura de movilización de creencias discursivas y extraordinarias. Es el lugar del imaginario social, la tierra natural de las ideologías teóricas y prácticas. La función del imaginario social es operar en el fondo común y universal de los símbolos, seleccionando los más eficaces y apropiados a las circunstancias de cada sociedad, para hacer marchar el poder. Para que las instituciones del poder, el orden jurídico, la moral, las costumbres, la religión, se inscriban en la subjetividad de los hombres, para hacer que los conscientes y los inconscientes de los hombres se pongan en fila. Más que a la razón, el imaginario social interpela a las emociones, a la voluntad y los deseos. Es un topos herográfico y teofánico sagrado por su función, aunque no siempre por su origen, pero con efectos seculares muy pragmáticos en lo social. Espacio-imago poblado de iconos, de mantos de púrpura, de mosaicos proféticos y miniaturas. En este espacio los rituales religiosos y profanos hacen su obra. Lugar de leyendas indocumentadas, de príncipes guerreros sentados en tronos de santos, y de santos con la espada desenvainada, símbolo de poder. Lugar de riendas que sujetan hermosos caballos, de hagiografías cromáticas, de sagas de nobleza, de rollos y tablas de la ley. Es un espacio de palmas levantadas, de piernas magras y desnudas, de bastones de mensajeros o enviados, de cruces griegas y signos bizantinos. Lugar donde algunas almas trepan en escaleras de treinta peldaños al paraíso y otras tropiezan por sus vicios y pasiones, donde las conductas, a la manera de los libros en los gestos imperativos de los códigos y los decretos gelasianos quedan repartidas en prohibidas y no prohibidas, recipiendiis

\section{y non recipiendiis.}

Son rituales ligados a estimular y promover comportamientos de agresión y seducción, las dos formas en que el deseo se anuda en el poder. Tienen una función claramente dogmática en el mismo sentido del ars juris, de la dogmática jurídica y de las antiguas escuelas medicinales que están a su base: suministrar esquemas de comportamientos rígidos y repetitivos, crear marcos de «praeceptio» (Praeceptum) en lugar de «perceptio» (perceptum) para poner en conexión regularidades de conductas con los fines o meta del arte del poder.

Jeremy Bentham en su Memoria sobre el Panóptico, esa obra maestra de arquitectura de la prisión, tuvo la genialidad de convertirla en modelo político de la sociedad, trazando a su alrededor uno de los más impresionantes ejercicios prácticos de razón utilitarista. Pero por impregnados de racionalidad que fuesen su texto y las operaciones constructivas con él vinculadas, Bentham fue muy lúcido en cuanto a la importancia del papel del imaginario social en el control de la disciplina de los hombres. Diversos pasajes de su obra lo ponen aquí y allá de resalto. Luego de proponer dar a los presos una máscara en la capilla para que el delito abstracto esté expuesto a la vergüenza, explica: «Una escena de esta especie sin darle colores demasiado negros, es tal en sí misma, que se imprimiría en la imaginación, sería uti- 
lísima para lograr el grande objeto del ejemplo, y la prisión se convertiría en un teatro moral, cuyas representaciones imprimirían el terror del delito».

«Es muy particular que la más horrible de todas las instituciones, presente en este punto un modelo esencial. La inquisición con sus procesiones solemnes, sus vestidos emblemáticos y con sus decoraciones espantosas, había hallado el verdadero secreto de mover la imaginación y de hablar al alma. En una buena organización de leyes penales, la persona más esencial es la que está encargada de combinar el efecto teatral».

Para Bentham, jefe de fila del imperativismo jurídico, no basta con las normas entendidas como mandatos, pues múltiples son las técnicas que convierten al imaginario en el más eficiente resorte de la obediencia, el control y el poder. El cuidado del aseo, por ejemplo, la regularidad de los baños, impedir el uso contrario a la práctica de las cosas más limpias, fijar los días en que se debe mudar la ropa, no son delicadezas necesarias para la salud. Tiene para él efectos normativos como si fueran commands, a la manera, diríamos, de las normas secundarias de Kelsen. Hay, señala, una conexión sutil entre delicadeza física y moral «que es obra de la imaginación». Por eso el aseo no es sólo una cuestión de limpieza. Acostumbra, por el lado del imaginario, a la circunspección, es un estimulante contra la pereza, enseña a respetar la decencia, patrimonio del poder, aun en las cosas más pequeñas. La pureza física tiene el mismo lenguaje que la moral. «Éste es el origen de aquellos sistemas de purificaciones y abluciones a que han dado una importancia tan minuciosa los fundadores de las religiones de Oriente, y por cierto que aun los que no creen en la eficacia espiritual de esos ritos sagrados, no negarán su influencia moral. La ablución es un tipo; ¡ojalá que sea una profecía!...».

Esta conexión que Bentham propone entre ablución, religión y efectos normativos en el marco y las metas del poder (el control social y la disciplina) hace que leamos sin sorpresa en el punto $6 .^{\circ}$ «Del aseo y de la salud» de su Memoria: «Ningún preso será puesto en una celda sin que antes sufra una ablución completa y sería conveniente que esa entrada fuera acompañada de alguna ceremonia solemne como algún rezo, una música grave, un aparato capaz de hacer impresión en almas groseras. ¡Cuán débiles son los discursos en comparación de lo que hiere a la imaginación por los sentidos!» 4 .

Los estudiosos de los sistemas penitenciarios saben que éstas y otras técnicas de manipulación de la obediencia al poder en función del imaginario estaban presentes en el más antiguo de los modelos de factura protestante, el Rasphuis de Amsterdam abierto en 1596: sistema de interdicciones poblado de exhortaciones, lecturas espirituales, manejos de los tiempos y los silencios para «atraer hacia el bien» y apartar las almas del mal. Un criminal no tenía que ser enfrentado con las bestias, sujeto a las galeras o enterrado en las minas como en otro tiempo. Tenía que ser enfrentado con su alma, en la exacta medida en que la ambición del poder era hacer de las almas un continuum, o prolongación de él. Lo que entra en práctica son técnicas de la pena-representación, de la pena-símbolo destinadas a golpear todos los

4 Jeremy Bentham: El Panóptico. «Memoria» en Principios de Legislación y de Codificación, Madrid, imprenta de Tomás Jordan, 1834, editado por Francisco Ferrer y Valas. 
sentidos, a despertar afectos dulces y honestos aptos para vehiculizar el discurso de la ley.

Decorados, afiches, marcas, efectos de óptica, bonetes, oraciones, recodifican el código, crean esquemas dogmáticos de repetición; organizan las emociones y los sentidos en la forma más adecuada para el reflejo o espejo de la dogmática jurídica o sintaxis del orden. Por constituir la mejor combinación de las emociones y sensaciones, puede decirse metafóricamente que constituyen también una sintaxis del imaginario en correspondencia con la sintaxis del orden jurídico. El uso, sin embargo, de los términos correspondientes, adecuación, espejo, reflejo, no debe inducir a pensar el vínculo entre uno y otro elemento del dispositivo del poder como una relación de correspondencia en el sentido fuerte de la palabra. En rigor, no hay correspondencia biunívoca, o uno a uno entre las sensaciones, emociones o demás componentes del imaginario social y los componentes del lenguaje de razón de la ley. Para decirlo en términos de la filosofía contemporánea: los componentes del imaginario social ejercen una función más pragmática que representativa. Se integran en formas sociales de vida, son Lebensform, actividades en las cuales el juego del lenguaje de los legistas es una parte. Pertenecen más al Wittgenstein de las Philosophische Untersuchungen (19, 23, 241) que al del Tractatus.

Mientras el discurso del orden combina predominantemente un repertorio de signos de la razón, el imaginario social teje signos alegóricos y anagógicos procedentes tanto de los fantasmas profanos como de la religión. Pero el entretejido global de estos signos con la fuerza y el discurso del orden no conforma una operación irracional, es por el contrario expresión de la más alta racionalidad del dispositivo del poder como condición de reproducción ideológica de la infraestructura económica de una formación social.

En ese dispositivo ideológico la función del imaginario es, en realidad, la de fundir y cincelar la llave de los cuerpos para el acceso de la ley. Su función es semejante a la que un comentarista jesuita, F. Courel, veía en los Ejercicios espirituales de I. de Loyola: construir el lugar temible y a la vez deseable de la ley. Constituir con el imaginario que rodea el «yo soy un pecador con cadenas delante de su juez» una fantasmática palanca de cambio hacia el «yo soy un caballero humillado delante de toda una corte y su rey» 5 .

Nadie como los cuáqueros supieron maniobrar con más plasticidad y fluidez en la prisión de Walnut Street, abierta en 1790, los elementos del imaginario para los fines del trabajo y la reinserción de los detenidos en la moral y la lógica del poder: la quietud del confinamiento, el manipuleo de los silencios, el reparto de los tiempos, los lugares y los trabajos, la meditación solitaria, toda una máquina de corrección para la puesta del hombre en relación con su contrición, para fortificar en él las relaciones de culpa con su crimen. Para despertar en él, como en un auténtico acto de remordimiento, todo el dolor y el pesar de haber ofendido al poder por ser quien es y porque se le debe amar sobre todas las cosas. 
No produce sorpresa que en esta coyuntura en que los protestantes tomaban la delantera sobre los católicos en la filantropía, se produjera en 1845 la única reedición de un pequeño opúsculo al parecer olvidado y sin influencias. Había sido escrito por uno de los benedictinos de la congregación de Saint Maur, el abate Jean Mabillon. En este Opúsculo titulado «Reflexiones sobre la prisión de las órdenes religiosas», detrás del llamado a la piedad para el tratamiento de los reclusos del claustro, no es difícil identificar la semejanza de diversos pasajes con los de la pluma de Bentham, de los cuáqueros y Benjamín Rush. «Es por esta razón -dice D. J. Mabillon- que en la elección de las penas que los jueces eclesiásticos deben emplear hacia los pecadores estén obligados a preferir aquellas que son capaces de imprimir en sus corazones el espíritu de compunción y de penitencia. De donde resulta que la mayor parte de las penas eclesiásticas sólo consisten en humillaciones y algunas penas aflictivas como el ayuno, la suspensión, la deposición, la excomunión, pero no en penas inflictivas que no son adecuadas más que a los tribunales seculares. La justicia que se practica en los monasterios contra los criminales debe imitar la conducta de la iglesia... todo debe ser aquí paternal puesto que se trata de la justicia de un padre hacia un hijo ». El insoportable Vade in pace, especie de prisión destinada a quienes debían allí terminar su vida, obra de Mahieu, prior de San Martín de los Campos según el informe de Pedro el Venerable, debía ser abandonado, critica Mabillon, y sustituido por un sistema donde los prisioneros encerrados in ergastulis, conforme al segundo Concilio de Verneuil de 844, fuesen macerados por penitencias adecuadas hasta que diesen señales de arrepentimiento y conversión. Su consejo es que los penitentes: «... quedan durante el oficio divino en la puerta del oratorio, como nos lo enseña el capítulo XLIV en la Regla y al fin de cada hora del oficio fuesen obligados a prosternarse a los pies de sus hermanos a la salida del oratorio...», ya que «Hay otras penitencias más útiles y más humillantes que la prisión. La suspensión del ejercicio de las órdenes, la inhabilitación para recibir órdenes sagradas, y sobre todo el sacerdocio, el último lugar en las asambleas de la comunidad, la privación de voz activa y pasiva, algunos trabajos extraordinarios...» ${ }^{6}$.

El imaginario social es una praxis en el mismo sentido que esta categoría tiene en la teoría aristotélica y en la marxista. Lo específico de esta praxis es la creación de lazos entre los códigos y el mundo. En esta praxis se hacen operantes los fantasmas y la subjetividad humana, pero en cuanto praxis pertenece a lo social. La palabra fantasma no alude al producto de una imaginación incontrolable o irracional, tiene el sentido de fantasma en la experiencia freudiana, tal como lo definen, Laplanche y Pontalis: no tanto la facultad de imaginar en el sentido filosófico y kantiano del término Einbildugskarft, sino de actividad creadora que anima el mundo imaginario (das Phantasieren) y sus contenidos. Estrictamente hablando el fantasma es: «Un escenario imaginario en el que se halla presente el sujeto y que representa... la realización de un deseo y, en último término, de un deseo inconsciente» 6 .

6 «Réflexions sur les prisons des ordres religieux» par Dom. J. Mabillon, Paris, Caen, ed. Charles Woinez, 1845.

7 J. Laplanche y J. B. Pontalis. Diccionario de Psicoanálisis, Barcelona, Madrid, Buenos Aires, Ed. Labor, 1971. 
En el imaginario social se realiza la conexión y el enlace entre el deseo y el poder. Sin duda la reflexión de Freud y su teoría psicoanalítica es la que más precisiones ha arrojado sobre la vida fantasmática del sujeto y su carácter relativamente organizado. Textos como La interpretación de los suenos, Formulaciones sobre los dos principios del funcionamiento psíquico, su célebre Estudios sobre la histeria con Breuer, son contribuciones esenciales sobre las diversas modalidades -como por ejemplo la de las Urszenen o «escenas originarias»- de examen del concepto psicoanalítico del fantasma en la realidad psíquica.

Pero la conexión fantasmática entre el poder y el deseo no pasó inadvertida para la teoría político-jurídica. En esa teoría del Estado que es el Leviathan, Hobbes propone la traducción en términos de necesidad social de este fenómeno psíquico. No lo hace sustituyendo el campo de la subjetividad interior por el de la sociedad. Lo hace más bien señalando la influencia de lo social en lo psíquico y la vía recíproca de realimentación del poder por lo psíquico. Para Hobbes suponer que el hombre puede vivir sin deseos, en el sentido de haber alcanzado un finis ultimus, es suponer que puede vivir aquel cuyos sentidos e imaginaciones se han detenido. Es como el reposo mítico de una mente satisfecha, como el bien-supremo o summum bonum de las obras de los antiguos moralistas. En rigor la felicidad es un continuo progreso del deseo de un objeto a otro, donde la obtención del anterior constituye el camino hacia el siguiente.

El objeto del deseo humano no es para Hobbes, disfrutar sólo una vez y por un instante, sino asegurar el camino de su deseo futuro. El objeto del deseo que privilegia Hobbes es el poder. Entre poder y deseo hay para él un vínculo fundamental dependiente de razones no sólo psíquicas sino de estricta naturaleza social: «De este modo -arguye- coloco en el primer rango a título de inclinación general de toda la humanidad, un deseo perpetuo y sin tregua de adquirir poder tras poder, deseo que no cesa más que en la muerte. La causa no es siempre esperar un goce más intenso que el ya obtenido, ni tampoco ser incapaz de contentarse con un poder moderado. En realidad, el hombre no puede asegurarse el poder y los medios del bienestar que actualmente tiene, sin la adquisición de más poder». En el lenguaje que empleamos en este trabajo esto equivaldría a decir que el poder requiere las condiciones sociales de posibilidad que aseguren su reproducción, condiciones que se enlazan con lo psíquico a través del imaginario. Por eso sucede, añade Hobbes, «que los reyes, cuyo poder es el más grande todos dirijan sus afanes a asegurarlo en el interior de sus dominios con las leyes y fuera mediante $_{8}$ la guerra. Y cuando todo eso se cumple, surge un nuevo deseo.... ${ }^{8}$.

Nadie como Albert Camus supo expresar con más penetración y belleza formal esta tendencia insaciable del poder a perpetuarse y trascender sus límites, en una obra que no es un ensayo político sino una pieza de teatro. En la escena XII de Caligula, el emperador, desasosegado, fatigado, enfermo en el alma por buscar la libertad mas allá de toda frontera, es aconsejado

8 T. Hobbes, Leviathan, Paris, ed. Sirey, 1971 con Int. y notas de François Tricaud, Cap. De la variété de moeurs. 
por Cesonia de dormir, de dejarse llevar por el sueño, de despreocuparse pues dispone del poder para amar lo que puede ser amado, y luego de la fatiga habrá de llegar el momento en que la mano vuelva a ser firme. Calígula, le contesta: «... ¿qué me importa una mano firme, de qué me sirve este asombroso poder si no puede cambiar el orden de las cosas, si no puede hacer que el sol se ponga por el este, que el sufrimiento decrezca, y que los que nacen no mueran? No, Cesonia, es indiferente dormir o permanecer despierto si no tengo influencia sobre el orden de este mundo» ${ }^{9}$.

Hacer que el cielo no sea cielo, mezclarlo con el mar, confundir belleza con fealdad, hacer brotar la risa del sufrimiento, igualarse a los dioses, ir más allá de los dioses, tomando a cargo un reino donde lo imposible es rey, era para Cesonia el sueño vesánico de un emperador, para Calígula, en cambio, el sueño muy lógico de la libertad, cuando todo esté nivelado, lo imposible por fin en la tierra, la luna en sus manos.

Esta articulación vesánica entre deseo y poder, la conversión del sujeto del poder en Dios para instaurar lo imposible en la tierra, es uno de los caminos que explican por qué el poder posible, el poder político y real consciente de sus limitaciones en la tierra, recurre histórica y habitualmente a un campo de referentes divinos o sus sustitutos seculares, en busca de legitimación y última garantía. Si no soy Dios, debe Dios o su Ersatz natural o racional ser la fuente o la referencia de mi poder.

Sabemos ahora que este campo es el del imaginario social. Se trata de un campo generalmente descuidado por la teoría política y jurídica, de tendencia tanto iusnaturalista como positivista, más preocupadas por construir los montajes referenciales en sus respectivas regiones de lo divino y lo natural o de la justificación racional, que en desmontarlos o producir una reflexión crítica sobre sus modos de funcionar.

Mucho es posible aprender sobre este funcionamiento en textos no estrictamente jurídicos, producidos por religiosos y no religiosos, como entre otros los de Dante, Nicolás de Cusa, Juan de Salisbury, G. de Ockam, Agustín de Hipona, Tomás de Aquino, Ignacio de Loyola, y más recientemente el cardenal Henri de Lubac ${ }^{10}$. Y ello, porque el imaginario social es, en última instancia, la aureola sagrada y profana de la ley: el lugar de sus últimas referencias.

Tal lugar, cabe repetir, no es otro que el de las ideologías teóricas y prácticas que tienden a motivar, movilizar e impulsar las creencias en favor del poder. Es exacto que en determinadas circunstancias históricas de contestación, de impugnación social y revolución contra el poder estas ideologías suelen perder su eficacia material o disminuir su valor conceptual y ser reemplazadas por lo que Luis Althusser llamó en la década del sesenta «Aparatos represivos del Estado» o sea aquellos con predominante recurso a la violencia, entre los que nombra a la policía, las cárceles, los tribunales, el ejército. Pero en épocas de sociedad paradigmática o normal, para expresarlo en lenguaje del acervo kuhniano, estas ideologías actúan, a pesar de su carácter fantasmático en el doble significado de fantasma y fantasía, con ope-

9 Albert Camus, Calígula, Buenos Aires, ed. Losada, 1982, acto, I, p. 67.

${ }^{10}$ Henri de Lubac, Corpus Mysticum, París, 1949, $2^{\text {a }}$. ed. 
ratividad natural, espontánea y no encrespada o compulsiva. Con ella, y a través de ellas, el poder se hace armónico, casi diríamos trivialmente armónico, en el sentido de homogéneo y cohesivo a la sociedad.

Las formas del imaginario social decoran el poder en el sentido de que lo embellecen y cubren de ornamentos, y en el sentido del decoro, de fijar el régimen de respeto y reverencia, de gravedad, y dignidad que reclama el poder, sea que esto proceda de recompensar una vida con una estatua, honrar una frente con hojas de laurel, satisfacer con una insignia el escudo de un linaje. Como en las novelas de Tolstoi, para llegar a ser 'comme il faut', los caballeros estaban condicionados a ocultar las molestias que ocasionaba el conseguirlo, también el imaginario crea un régimen de buenas maneras y educación que permite al poder ocultar las molestias (las violencias) ocasionadas en conseguirlo.

Hemos explicado hasta aquí, luego de dar distintos ejemplos de formas del imaginario social, las razones internas o endógenas al dispositivo del poder, que hacen que esas diversas formas se ensamblen y tengan un distinto régimen de junturas con el discurso del orden según los cambios históricos. Por ejemplo, el derecho germánico estaba vinculado en la Edad Media a una serie de símbolos, algunos de los cuales subsisten hoy en tanto otros han desaparecido, y que se modificaban con el régimen del poder. Así, das Banner (el estandarte) se diferenciaba de die Fahne (la bandera), incorporándose el primer nombre en el siglo XIV bajo Karl IV, procedente de la palabra francesa Bannière, pero su uso era más antiguo, correspondiendo die Fahne a los círculos francos. Originariamente sólo el soberano tenía el derecho a levantar el estandarte (das Banner) y con ello invitar a sus secuaces a la guerra. Un estandarte rojo era el símbolo de la jurisdicción judicial, de la Gerichts-und Hinrichtungstätte. Con el advenimiento del sistema feudal, y el cambio de régimen del poder, el derecho a erigir el estandarte fue transmitido por el Rey a los vasallos de más alto rango, mientras que los vasallos más bajos sólo podían portar banderas (Fahne). Una larga lista compone la Rechtsymbolik de los germanos como la sangre, en la cofradía o hermandad de sangre; el hilo rojo protección de los tribunales de justicia; el fuego, símbolo de la pureza acreditada en los distintos modos del juicio de Dios; la entrega de un ramo verde (Grüner Zweig) como símbolo de traspaso de la propiedad de un gran dominio; Gürtel o cintas como símbolo de fuerza y dominio. El crecimiento del pelo un tiempo después de la muerte captado como símbolo de fuerzas mágicas. El pelo largo y la barba como signo de la valentía, la libertad y la nobleza de los señores. El tallo (Halm) como símbolo del traspaso en donación de la gran propiedad. El agua como símbolo de la pureza a acreditar en la prueba del agua del juicio de Dios (Gottesurteil), y la elección de un sitio cercano al agua santa para erección de los tribunales (Gerichtstätte).

Todos estos símbolos, y otros como los colores rosa y lila, las pieles, los guantes, la cruz, el velo (Schleier), la espada (Schwert), la jabalina (Speer), el bastón (Stab), los estribos (Steigbügelhaften), el manojo de pajas (Strohwisch), la silla (Stühl) y el cetro (Zepter), relacionados con el dominio, el régimen de propiedad, la prueba procesal, la condición de clase, derecho del poder a la jurisdicción, etc., experimentaron modificaciones con las rota- 
ciones en el poder y sobre todo en contacto con el cristiano ingresaron en las costumbres de éste o, luego de la cristianización cayeron en el olvido ${ }^{11}$.

Dijimos que las razones internas al dispositivo del poder que determinan el régimen de acople de éstas y otras prácticas con el discurso del orden, se vincula con la circunstancia de que la tópica del imaginario social, su rol y función difiere respecto del carácter predominantemente racional de ese discurso. Pero existen también razones de orden endógeno, externas, por así expresarlo, al dispositivo del poder, dado que sus elementos son instancias superestructurales en el conjunto de la sociedad.

Las grandes transformaciones económicas, los cambios en los sistemas de producción y, consecuentemente, en el régimen de propiedad, determinan una reestructura y reajuste del dispositivo del poder.

Esta reestructura y reajuste es exógena al dispositivo, pero esto no hay que entenderlo como que los cambios procedentes de la base económica tanto en estos períodos de crisis o revolución como en los más estables en que la sociedad no ha perdido su identidad histórica, constituyan algo así como una duplicación de los cambios interiores a ese dispositivo. Constituyen, empero, el eje básico de la combinación de lo que antes llamamos sintaxis del orden y sintaxis del imaginario. Aquí endógeno y exógeno no apuntan a dos regiones independientes de la sociedad que haya luego que acoplar. Aluden, más bien, a distintos niveles de análisis. El endógeno se mueve en el plano de las diferencias de función de los elementos del dispositivo del poder, de su heterogeneidad, de su distinta tópica, para ver, por ejemplo, lo imposible de considerar al derecho como pura fuerza o pura ideología, haciendo de él la gran noche en que «todos los gatos son pardos» como gustaba a Hegel decir del absoluto de Schelling. O, por el contrario, atrincherarlo en su historia interna, vaciarlo de su contenido de discurso del orden, evacuar sus modos de alinearse con los otros tipos de discurso y el régimen imaginario de su activación.

El exógeno es, en cambio, nivel de análisis de la relación del dispositivo del poder con la estructura económica. En este nivel, el dispositivo del poder y cada una de sus instancias no son independientes del modo en que una sociedad produce sus formas de vida. Aunque dada la irreductibilidad del dispositivo y su autonomía relativa -coordenadas de sistematización del arsenal teórico de Althusser y Poulantzas- se hace significativa una de las propiedades del dispositivo en relación a una base que no se auto-estructura: fijar las condiciones de realimentación y reproducción de las formas económicas de vida producidas.

Así como el imaginario social es condición de reproducción del discurso del orden en el dispositivo del poder, el dispositivo del poder, enfocado en su modelo político-jurídico, es condición de reproducción de las formas de producción.

11 Justiz in alter Zeit, Band VI, by Mittelalterliches Krimminalmuseum, Rothenburg, Drukerei Schulist, Heilsbroom, 1948, cap. Rechtssymbolik, p. 467. 


\section{2}

\section{-HOBBES Y KELSEN: los referentes profanos del poder}

Ahora bien, teniendo en cuenta la especificidad de las instancias del discurso del orden y la pluralidad de modalidades en que este discurso es reactivado por el imaginario social, es posible practicar análisis concretos, en circunstancias históricas concretas, de las formas conceptuales o materiales de inserción del imaginario social en el discurso jurídico y político.

Una de estas formas ya fue enunciada: el montaje de los referentes profanos y sagrados de legitimación del derecho y de la teoría del Estado. Con el pacto social, con las convenciones por las cuales se atribuye el poder absoluto al soberano en las repúblicas de dominio o de institución, Hobbes ofreció en el Leviathan un ejemplo recurrente, aunque matizado, en la teoría del poder. Esta justificación final obedece a un determinado procedimiento técnico: dar a una ficción, del tipo y naturaleza de las que siglos más tarde tratará y sistematizará Hans Vaihinger en Die Philosophie des 'als ob', el carácter de una ficción fundadora. Si no existen evidencias históricas del pacto social, para entender la sociedad, en el caso para comprender el poder absoluto, debo proceder «como si» se hubiera suscripto un pacto en que los hombres ceden al soberano la libertad de que disfrutan en el estado de naturaleza para recibir en contraprestación la paz y la seguridad, o sea por cálculos de la razón. La ficción es un procedimiento racional en un doble aspecto: el «como-si» tiene una función de conocimiento. En el contexto de Vaihinger es una ficción cognoscitiva, pertenece al dominio del Erkenntnislehre puesto en juego para comprender el poder por cuenta de otra escena: la ausente realidad histórica que lo instaura. En función de este carácter racional pertenece al tejido mismo de un discurso racional, el del orden. Pero es racional también dado el sentido y utilidad de su mecanismo: por la ficción, la convención o el pacto, engendran las condiciones de su propia realidad. El principio del «como si» instaura el contenido de la convención misma que hace operantes y validas las leyes y disposiciones del poder.

No obstante, al funcionar la ficción como ficción fundadora, el principio cognoscitivo es, al mismo tiempo, principio de justificación. No se le pueden aplicar los criterios de verdad o falsedad, sino los de validez, o más bien de justicia en el sentido de justeza, de adecuación y conformidad de los mecanismos de la ficción con los intereses legitimantes del poder. La ficción es así puramente ideológica. El enunciado que la transporta constituye el síntoma de una realidad distinta de aquélla que él enfoca. La realidad histórica es la del acto de poder que instaura el poder absoluto; la realidad que enfoca el enunciado es la convención. La circunstancia adicional de que con el pacto el poder se presente para provecho de todos siendo que su instauración histórica lo es en provecho del poder absoluto, reduplica el carácter ideológico del enunciado que transporta la ficción. Este enunciado es, pues, ideológico en el sentido de que la ficción obra por cuenta de otra escena, e ideológico en el sentido de que la legitimación presenta como universales los intereses propios de los beneficiarios del poder. Que este doble carácter ideológico sea una constante del discurso del orden que acompaña a la sucesión 
del poder en el tiempo, es el fenómeno para el que suministran sus claves, las reflexiones de la teoría de la historia.

El equivalente del pacto social del pensamiento político de Hobbes en el seno de la teoría del derecho es otro referente racional y secular: la Grundnorm de Hans Kelsen. Esta norma es también una ficción destinada a dar en este otro marco, el último fundamento de validez del orden jurídico. En cuanto 'norma', en cuanto significado de un acto de voluntad dirigido a la conducta de otros, no existe en la realidad del derecho positivo, pero debemos actuar 'como si' existiera para comprender desde el punto de vista científico el derecho por un lado y, por otro, para justificarlo asignando a la ficción el contenido significativo de validez originaria de todo el sistema normativo.

En 1965 Kelsen redactó un ensayo «On the concept or norm» considerándolo capítulo primero de una obra más extensa, La teoría general de las normas, que por entonces, cercano a los 85 años, tenía la esperanza de concluir y que resultó a la postre su libro póstumo ${ }^{12}$.

En este trabajo, Kelsen sostuvo con carácter general la posibilidad de normas ficticias. Considerando la distinción entre un acto y el significado de un acto, puesta ya de relieve por H. Rickert en Logos I (1910) -que Kelsen acepta para su teoría con ciertas reservas- y encarando a partir de esta distinción la crítica del derecho natural procedente de la razón, sostiene que siendo ésta una capacidad cognoscitiva las normas del derecho de razón representan el significado de actos de pensamiento. No son normas queridas (willed norms) sino normas pensadas. Ahora bien, añade, hay por cierto normas meramente pensadas, en contraste con normas puestas por actos reales de voluntad. Su tipo es muy especial: se trata de normas meramente pensadas que no constituyen el significado de actos de pensamiento, sino de actos de voluntad sin lugar en la realidad, pero pensadas e imaginadas tal como se puede pensar o imaginar cualquier cosa posible carente de existencia real. Sólo puedo pensar de tal norma como el significado de un acto de voluntad que la acompaña. Aclarando acto seguido el sentido vaihingeriano de esa norma «I can think of a norm 'as if' it were posited by an authorit y, although it has not actually been posite, and ther is actually no act of will whose meaning it is» (Puedo pensar de una norma 'como si' fuere puesta por una autoridad, aunque no haya sido realmente puesta y no haya realmente acto de voluntad cuyo significado es la norma).

De este modo Kelsen recurre al mecanismo de las ficciones del 'como si' y lo hace, en el contexto de este artículo, con carácter general con el fin de preservar un principio fundamental del positivismo: no existe un «usted debe» sin un «yo quiero», no hay imperativos sin «imperator». Aun si «... the authoritative act of will wich has the merely thought norm as its meaning is a ficticious one» (aun si «... el acto autoritativo de voluntad que tiene la norma meramente pensada como su significado es ficticio»).

Este recurso de Kelsen a normas ficticias del 'como si' puede quizá sorprender a un lector de medio siglo antes, al lector del Kelsen que en 1911

12 Hans Kelsen, «On the concept of norm» en Essays in legal and moral philosophy, Holland, Reidel Publishing Co., Chap. IX, int. O. Weinbeger. 
ya en el prefacio de Hauptprobleme der Staatlehre -la obra que preanuncia buena parte del tejido de su influyente Teoría pura del derecho- expresara como timbre de honor de un pensamiento científico el llevar a cabo la más dura batalla contra las ficciones: «La combinación de puntos de vista mutuamente excluyentes conduce necesariamente a la ficción, a la afirmación de una realidad en contradicción consciente con el estado de cosas. Y nada es más característico para el estado actual de la ciencia jurídica, que el que su teoría esté entremezclada de ficciones. Una de las metas de mi libro es la lucha contra la ficción, esa reprochable mentira inocente de la ciencia» («... Der Kampf gegen die Fiktion, diese verwerfliche Notlüge der Wissenschaft, is eines der Ziele meiner Arbeit») ${ }^{13}$.

Sin embargo, en ese medio siglo que corre entre los Hauptlehre y «El concepto de norma», Kelsen matizó mucho su posición originaria sobre las ficciones jurídicas. En este aspecto su biografía intelectual guarda mucha semejanza con la de Jeremy Bentham que también experimentará notorios cambios en su aprehensión del problema de las ficciones en el derecho ${ }^{9}$. En primer lugar, Kelsen no fue indiferente a la intensa polémica desatada por la filosofía del 'como si' en los años veinte que comprometió particularmente a extendidos medios intelectuales y académicos de lengua germana. Lo más rico de esta polémica obtuvo recepción en los famosos Annalen der Philosophie und philosophischen Kritik dirigidos por Joseph Petzoldt, Raymund Schmidt y el mismo Hans Vaihinger. Vaihinger, el jefe de fila de la teoría, se vio favorecido en el campo del derecho por una activa escuela de adherentes como R. Mallachow, C. Schmitt, P. Krückmann, W. Hofacker, W. Strauch, y otros. Como contribución a esta polémica, Kelsen produjo un artículo muy rico «Acerca de la teoría de las fícciones jurídicas con especial consideración de la filosofía de Vaihinger del 'como si'», en el que recoge el concepto de ficción respecto de la teoría del conocimiento aplicándolo en particular a la teoría jurídica y no aceptando, en cambio, que las ficciones legales legislativas y judiciales constituyan una verdadera ficción en el sentido de Vaihinguer, porque su propósito no está dirigido a la verdad; en rigor no son verdaderos medios de conocimiento» (Erkenntnismittel) ${ }^{14}$.

Sin discutir las tesis aquí desenvueltas, lo que demuestra la contribución de Kelsen junto con la coyuntura teórica y el ambiente de ideas efervescentes en que se produce, es su familiaridad con la cuestión del 'como si'. $\mathrm{Y}$ esto es significativo, pues es esa familiaridad lo que le va a permitir en 1962 , o sea tres años antes de «On the concept of norm», singularizar y concretar lo que hace en este texto con carácter general, introduciendo la ficción en la médula misma de todo su sistema teórico del derecho: la noción de norma fundamental.

En una discusión referida en Das Naturrecht in der politischen Theorie, reconoce su error al haber considerado durante largo período a la Nor-

Hauptprobleme der Staatlehre, entwickelt aus der Lehre vom Rechtssatze, Tübingen, 1911, p. VIII.

14 La obra de Han Vaihinger es Die Philosophie des 'Als $\mathrm{Ob}$ ', cuenta con una introducción sobre Kant y Nietsche. Fue editada por Felix Meiner, Verlag, Leipzig, 1920. Vaihinger fue el fundador de Der Kant-Gesellschaft y de los conocidos Kant-Studien. 
ma Básica como una «hipótesis» y en 1964 da forma a su nuevo concepto, en su ensayo «Die Funktion der Verfassung» (Forum, Viena, p. 583-6) ${ }^{15}$.

Kelsen se topa con el problema de que a una norma presupuesta en el pensamiento jurídico, y no puesta a través de un acto real de voluntad, se le puede objetar que una norma sólo puede ser el significado de un acto de voluntad (Willensakt) y no un acto de pensamiento (Denkakt), puesto que hay una importante correlación entre el Sollen (deber) y el Wollen (querer). La única manera de precaverse, dice, de esta válida objeción es confesando (zugeben) que junto con la norma básica pensada se debe suponer una autoridad imaginaria cuyo acto fingido de voluntad tiene tal norma básica como su significado. Ahora bien, arguye Kelsen, con esta ficción, el aceptar la norma básica de este tipo engendra una contradicción con el reconocimiento de que la constitución (histórica), cuya validez está fundada en aquella norma, es el significado de un acto de voluntad de una autoridad suprema sobre la cual no puede ser admitida ninguna otra. «Así, agrega, la Norma Básica constituye una genuina ficción en el sentido de la filosofía vaihingeriana del 'como si'. Una ficción en este sentido está caracterizada no sólo por contradecir la realidad, sino por ser auto-contradictoria».

De este modo, la Grundnorm se erige en los términos técnicos del lenguaje de Vaihinger en una ficción real o completa a diferencia de las semificciones que contradicen la realidad, pero no se contradicen a sí mismas.

La norma básica que diga, por ejemplo, «El orden jurídico debe comportarse como lo determina la constitución histórica» contradice no sólo la realidad, en la que no existe tal norma como el significado de un acto de voluntad, sino también es auto-contradictoria pues presenta el poder (die Ermächtigung) de una suprema autoridad y, con ello, una autoridad emanada de otra que está por arriba, aun cuando esta autoridad consecutiva fuese meramente imaginada...» «Con esto -concluye- es de observar que la Grundnorm en el sentido de la filosofía del 'como si' de Vaihinger no es ninguna hipótesis -como yo mismo lo he caracterizado a veces- sino una ficción, la que se diferencia de una hipótesis en que es acompañada o debe serlo de la conciencia de que ninguna realidad le corresponde».

Esta rectificación de Kelsen, esta distinción, entre hipótesis (como hipótesis trascendental kantiana) y ficción, el abandono de la primera por Kelsen, y su reiteración del concepto de ficción de la Norma Básica en su Allgemeine Theorie der Normen (p. 206-7), es importante. No tanto en el sentido de que constituye un verdadedo «swan song», un canto de cisne de la teoría como lo dice su comentarista Ian Stewart preocupado por defender la tradi-

15 La discusión fue referida en las págs. 119-120 de dicho texto Das Naturrecht in der politischen Theorie ed. por Franz-Martin Schmölz, y extractada por Karl Olivecrona en Law as Fact, 1971, 2a. ed. p. 114, según hace constar Ian Stewart, traductor e introductor del artículo posterior de Kelsen al inglés «The basic Norm \& Fiction» en The Juridical Review. The Law Journal of Scottish Universities, Edimburgh, W. Green and son. El texto alemán «Die Funktion der Verfassung» está en la pag. 1961 de Die Wiener Rechtstheoretische Schule, Schriften von Kelsen, Merkl y Verdross. UV. Anton Puset, Europe Verlag Wien, 1968. 
cional imagen del Kelsen neo-kantiano ${ }^{16}$. Al fin y al cabo, también Vaihinger admite la fuerte influencia de Kant sobre su pensamiento, junto con la de Schopenauer, Lange, el positivismo y el empirismo de John S. Mill, en el prefacio de la segunda edición de su obra más significativa ${ }^{17}$.

Lo es, en cambio, en mi opinión, porque la transformación de la Norma Básica de hipotesis del conocimiento jurídico en ficción que implanta un acto de voluntad suprema fingido, hace depender todo el edificio del discurso del orden (Kelsen no señala diferencias, respecto de la Norma Básica, entre el derecho y la moral) de una función fundadora, de un mito originario.

Y esto da mucha mayor transparencia a su pensamiento anterior. Torna más desnudo, por así decirlo, que en la parte más racional del discurso del orden, viene a insertarse y articularse, directamente en el tejido del mismo, el imaginario social. La ciencia jurídica es instrumento de conocimiento y justificación (legitimación del poder) al mismo tiempo, y aunque esto haya estado ya presente en el pensamiento kelseniano anterior, no lo estaba el ingreso del imaginario social, el entrecruce de la racionalidad del discurso del orden con la tópica de las ideologías teóricas y prácticas que constituyen la condición de su reproducción. El punto de engarce, en este caso, la modalidad de la combinación es una ficción, el montaje de un mecanismo de un último referente secular semejante en su función a los referentes divinos.

Los juristas saben que tendencias distintas a la línea kelseniana han propuesto otros procedimientos de referencia, y últimos fundamentos, en sus procesos de justificación racional de la ley, aun cuando la Grundnorm haya sido la de mayor fuerza y persistencia en nuestra centuria. Saben también que en el campo de las referencias divinas la religión ha sido la fuente de mayor inspiración para los juristas, y que éstos, tomando en cuenta sus modelos y distintas figuras del imaginario social promovidas por la religión, legitimaron o desautorizaron a determinadas fuerzas políticas en el juego histórico de sus relaciones, convirtiendo al discurso del orden en poderoso instrumento en la lucha por el poder. En abundantes trabajos, como «Dios y el Estado», «El alma y el derecho», «las relaciones entre el Estado y el Derecho a la luz de la crítica del conocimiento», «El concepto de Estado y el psicoanálisis», «Los fundamentos filosóficos del derecho natural y el positivismo jurídico», «El concepto de Estado y la psicología social con especial referencia a la teoría de las masas según Freud», pasando por la Teoría Pura del Derecho hasta Teoría General de las Normas, Kelsen fue uno de los pensadores del derecho que trató con mayor continuidad y penetración el parelelismo entre el pensamiento social y el religioso y la recurrente referencia a Dios del pensamiento jurídico ${ }^{18}$.

16 Allgemeine Theorie der Normen, de Hans Kelsen fue dada a luz por encargo del HansKelsen-Institus según el Nachlass editado por Kurt Ringhofer y Robert Walter. Wien, 1979, Manzsche Verlag. El artículo de Ian Stewart es el citado en nota 15.

17 Op. de Vaihinger, nota 14. Vaihinger reconoce esta deuda intelectual en la int. de su libro.

18 «El alma y el derecho» consta en Droit, Morale, Moeurs, II Annuaire de l'Institut internationale de philosophie du droit et de la sociologie juridique. Paris, 1936. El resto de los arts. citados, salvo «El concepto de Estado y la psicología social con especial 
Ala luz de estos, y otros trabajos, los juristas pueden verse estimulados a investigar casos históricos concretos, portadores de modalidades especiales de funcionamiento del imaginario social en relación con el discurso del orden, dentro del dispositivo del poder. Aunque quizá no dejen de calibrar como un dato peculiar de la biografía del teórico del derecho de más vasto peso en el siglo, que quien dedicara toda una vida intelectual a desmontar las referencias divinas de fundamentación imaginaria del poder, haya sido el arquitecto profano del más solido artefacto de conexión entre discurso de razón e imaginario social: la Grundnorm.

referencia a la teoría de las masas según Freud» pub. por Rev. Imago, 1922, costan en Die Wener Rechtstheoretische Schule, op. cit. nota 15.

Sobre las referencias divinas en Kelsen véase el excelente y documentado artículo de François Ost y Michel var de Kerchove, «La référence à Dieu dans la théorie pure du droit de Hans Kelsen», Ed. Facultés Universitaires de Bruxelles, Belgique. 